\title{
How accurate are energy intensity projections?
}

\section{CCEP Working Paper 1706 April 2017}

\section{David I. Stern}

Crawford School of Public Policy, The Australian National University

\begin{abstract}
Recent projections of energy intensity predict a more rapid decline in intensity than has occurred in the recent past. To assess how well such projections have performed in the past, I assess the accuracy of the business as usual energy intensity projections embedded in the annual World Energy Outlook (WEO) produced by the International Energy Agency since 1994. Changes in energy intensity depend on economic growth and historical errors in projecting energy intensity can partly be explained by errors in projecting the rate of economic growth. However, recent projections of the elasticity of energy intensity with respect to economic growth probably overstate the likely future reduction in energy intensity even if economic growth is projected accurately. This could be because energy efficiency policies are not implemented as effectively as expected or because the economy-wide rebound effect is larger than modeling assumes.
\end{abstract}




\section{Key words:}

Integrated Assessment Models, Business as Usual, Projections

JEL codes:

Q43, Q54

\section{Suggested Citation:}

Stern, D. (2017), How Accurate are Energy Intensity Projections? CCEP Working Paper 1706, April 2017. Crawford School of Public Policy, The Australian National University.

\section{Address for Correspondence: \\ David I. Stern \\ Crawford School of Public Policy, The Australian National University \\ E-mail Address: david.stern@anu.edu.au}

The Crawford School of Public Policy is the Australian National University's public policy school, serving and influencing Australia, Asia and the Pacific through advanced policy research, graduate and executive education, and policy impact.

The Centre for Climate Economics \& Policy is an organized research unit at the Crawford School of Public Policy, The Australian National University. The working paper series is intended to facilitate academic and policy discussion, and the views expressed in working papers are those of the authors. Contact for the Centre: Dr Frank Jotzo, frank.jotzo@anu.edu.au 


\title{
How Accurate are Energy Intensity Projections?
}

David I. Stern

Crawford School of Public Policy, The Australian National University, 132 Lennox Crossing, Acton, ACT 2601, Australia. david.stern@anu.edu.au. Phone: +61-2-6125-0176.

ORCID: 0000-0001-6595-4268

18 April 2017

\begin{abstract}
Recent projections of energy intensity predict a more rapid decline in intensity than has occurred in the recent past. To assess how well such projections have performed in the past, I assess the accuracy of the business as usual energy intensity projections embedded in the annual World Energy Outlook (WEO) produced by the International Energy Agency since 1994. Changes in energy intensity depend on economic growth and historical errors in projecting energy intensity can partly be explained by errors in projecting the rate of economic growth. However, recent projections of the elasticity of energy intensity with respect to economic growth probably overstate the likely future reduction in energy intensity even if economic growth is projected accurately. This could be because energy efficiency policies are not implemented as effectively as expected or because the economy-wide rebound effect is larger than modeling assumes.
\end{abstract}

Keywords: Integrated Assessment Models, Business as Usual, Projections

\section{Acknowledgements}

I thank Ken Baldwin for inviting me to give a presentation on the 2016 World Energy Outlook at the ANU Energy Change Institute 2016 Energy Update. I thank Stephan Bruns, Paul Burke, Bob Costanza, Ida Kubiszewski, and two anonymous referees for their very helpful comments. I also thank the Australian Research Council for funding under Discovery Project (DP160100756) "Energy Efficiency Innovation, Diffusion and the Rebound Effect."

\section{Competing Interests}

The author declares no competing financial interests. 
The future development of energy intensity - the ratio of energy use to gross domestic product (GDP) - is of interest both for projecting future energy demand based on projections of economic growth and, as one of the factors in the Kaya Identity, future greenhouse gas emissions. Marangoni et al. (2017) show that energy intensity is one of the two more important Kaya factors together with the rate of economic growth. If we are over-optimistic about the potential for limiting the increase in energy use under business as usual (BAU), climate policy may be weaker than it needs to be. Various researchers and organizations routinely project future energy intensity. Recent projections tend to predict faster reduction in energy intensity than has occurred in recent history. The IPCC $5^{\text {th }}$ Assessment Report integrates projections from many different models (Clarke et al. 2014 Figure 6.1) finding that $95 \%$ of models predict that energy intensity will decline more rapidly than in the past. The 2016 World Energy Outlook (WEO-2016) also projects more rapid decline in energy intensity in the future under the "Current Policies" scenario than has occurred in the last couple of decades (Figure 1). ${ }^{1}$ Here, I investigate how well the $W E O$ has projected changes in energy intensity to date and evaluate the prospects for achieving such a rapid decline in the future.

The mean rate of decline of world energy intensity from 1990 to 2015 was $1.46 \%$ p.a. (Figure 1). WEO-2016's Current Policies projection sees energy intensity declining by $2.09 \%$ p.a. till 2020 and by $2.13 \%$ p.a. between 2020 and 2030, after which the rate moderates to $1.7 \%$ p.a. ${ }^{2}$ Energy intensity did decline more rapidly than this in a few recent years during the later years of economic booms. But these were exceptions. In the immediate aftermath of the Great Recession of 2008-9, energy intensity actually increased (Jotzo et al. 2012) and its decline was quite slow in the early part of the previous boom too. The New Policies scenario expects more rapid decline still in future energy intensity.

Though the projected rate of decline under BAU is more rapid than that in the recent past this

\footnotetext{
${ }^{1}$ Following IEA practice, I refer to each annual WEO by attaching the date of publication with a hyphen. The "Current Policies" scenario assumes that only energy and climate change policies that are already implemented will be in place in the future. The IEA's "New Policies" scenario assumes that other policies that have been announced but not yet implemented will be implemented. In WEO-2016 this includes policies that countries agreed to as part of the Paris Climate Change Accord (IEA, 2016)

${ }^{2}$ IEA makes projections for the level of energy use for a number of specific years in the future - in WEO-2016 2020, 2030, and 2040 for the Current Policies scenario. I derived these rates of change in energy intensity from IEA's stated assumptions on the future rate of economic growth and their projections of the level of energy use at these future dates. IEA makes both global and regional projections. Here, I only analyze the global projections.
} 
does not mean that it is impossible. Perhaps there are good reasons why the decline should accelerate. How well have past projections matched subsequent reality? The WEO provides a good case study, as the IEA has published the WEO annually since 1993 (with the exception of 1997) and most editions contain a Baseline, BAU, Reference, or Current Policies projection of world economic growth and energy use. I analyze projections of economic growth and energy use in all WEOs published since 1994, which are available online to find out how well they have projected energy intensity to date. Of course, the IEA has always warned that real world developments may turn out differently to what they expected at the time of projection (IEA, 1994 to 2016). Still, it is important to know if there is a systematic bias in these projections rather than simply random forecast errors.

Researchers have previously assessed how well the WEO has projected the Reference scenario for solar PV and other renewable energy technologies (Metayer et al. 2015) and how well IPCC reports have projected carbon dioxide emissions intensity (Pretis and Roser 2016). ${ }^{3}$ Metayer et al. (2015) analyze projections in all WEOs from 1994 to 2014. They find that the growth of solar technologies and wind energy has been consistently strongly underestimated, suggesting that there could be systematic biases in the underlying modeling. The IEA also assessed past $W E O$ projections for OECD primary energy demand and world oil demand (IEA 2000). They found that the WEO-1993 to WEO-1995 underestimated OECD energy demand to 2000 while WEO-1996 and WEO-1998 overestimated it. The cumulative deviations by 2000 were, however, small ranging from about $-1.5 \%$ to $+0.75 \%$.

Figure 2 shows, for each $W E O$, how much faster or slower energy intensity changed in subsequent years relative to the projection. Positive deviations indicate that energy intensity declined slower than it was projected to and vice versa. Intensity declined slightly slower in following years than WEO-1994 to WEO-1996 projected. Then from WEO-1998 to WEO2003 energy intensity declined much faster in subsequent years than projected. Finally, from $W E O-2004$, with the exception of WEO-2014, the projections have been overoptimistic about the rate of decline in energy intensity.

It turns out that the correlation between these cumulative projection errors and the respective cumulative projection errors in GDP is -0.8. Csereklyei et al. (2016) show that the rate of

\footnotetext{
${ }^{3}$ Other studies such as Aleklett et al.'s (2010) review of WEO-2008's projection for world oil production do not compare projections to actual outcomes.
} 
change in energy intensity is negatively correlated with the rate of economic growth and that in the absence of economic growth energy intensity tends to increase slowly. However, IEA uses external projections of GDP growth and a better assessment of the performance of the projections would remove the effect of economic growth.

We can use an identity decomposition to investigate the role of economic growth rate projections in projections of energy intensity. I denote the growth rate of energy intensity by $g(E / Y)$, where $E$ is global energy use, $Y$ is total GDP, and $g($.$) is the average percentage$ growth rate over a given period. Then multiplying and dividing $g(E / Y)$ by the growth rate of GDP, $g(Y)$, we have:

$$
g(E / Y) \equiv \frac{g(E / Y)}{g(Y)} g(Y)
$$

The term $g(E / Y) / g(Y)$ can be seen as the elasticity of energy intensity with respect to economic growth assuming that the rate of decline in energy intensity is zero in the absence of economic growth. Figure 3 presents actual and projected $g(E / Y) / g(Y)$ from the base year of each WEO to either 2015 or 2010 . The realized elasticity has increased (in absolute value) over time from around -0.3 to $-0.6 .^{4}$ The major changes in the elasticity are associated with events in 2010 when energy intensity increased (Figure 1). The projections of WEO-1994 to WEO-1996 end in 2010. Hence the realized elasticities through 2010 are relatively small. 2010 is included in the projection periods for WEO-1998 to WEO-2011 but the following years up to 2015 are included in the calculations of the elasticity. From WEO-2012 on, 2010 is no longer included in the projection period and there is a sharp fall in the realized elasticity as a result. This suggests that the range of values from WEO-1998 to WEO-2011 is likely to be more representative of the long-run value of the elasticity.

Figure 3 shows that WEO-1994 to WEO-1996 overestimated the elasticity. From 1998 to 2001 the WEO estimated smaller elasticities, but these underestimated the actual elasticities. Since then the projected elasticities have become larger. WEO-2009 to WEO-2011 overestimated the elasticity, which was influenced by the increase in energy intensity in 2010. From 2012, that increase in energy intensity was no longer in the projection period and the realized elasticity increased. WEO-2012 to $W E O-2015$ then under-estimated the elasticity.

Figure 4 decomposes the errors in projected energy intensity in Figure 2 into the parts due to

\footnotetext{
${ }^{4}$ From here on, when comparing values of the elasticities, absolute values are assumed.
} 
the error in projecting the elasticity and the error in the projected economic growth rate. I compute (1) for each projection period by substituting on the right hand side of (1) the projected elasticity, $g(E / Y) / g(Y)$, but the actual realized growth rate of GDP, $g(Y){ }^{5}$ Through 2001, the two components of the projection error are highly positively correlated ( $r$ $=0.995)$. From 2002 to 2016 the correlation is -0.33 with an overall correlation for the full period of 0.12. The mean absolute value of the two error components is similar with the role of growth rate errors increasing relative to elasticity errors over time.

Explaining changes in the behavior of the elasticity projection error over time has to be somewhat speculative, but we can point to some potential factors. The number of variables about which assumptions are made in IEA's modeling has changed over time, as has the number of explicit policies that the modelers have tried to take into account. In the earliest reports, the rate of economic growth, the future development of energy prices, the future development of energy efficiency in some sectors, future power generation capacity, and energy policies, in terms of taxes on energy, were all fed into the model that produced the energy use projection (IEA 1994, 1995, 1996). WEO-1998 was based on a new world energy model (WEM, IEA 1998). In particular, additions to power generation capacity were modeled as an outcome of an economic optimization decision.

In WEO-2000 the BAU scenario was replaced with a Reference scenario that took into account specific new energy and climate change policies in OECD countries (IEA, 2000). However, these changes do not have an apparent effect on the elasticity itself in Figure 3 or on the behavior of the elasticity projection error in Figure 4, which was highly correlated with errors in the rate of economic growth through WEO-2001.

“The WEM underwent a major overhaul in 2004" (IEA 2006 p. 55), which was further extended in following years (IEA 2006, 2007). This allowed more detailed modeling of specific energy policies and measures (IEA, 2006). The 2004 revision coincides with larger positive elasticity projection errors in Figure 4 and an increase in the elasticity in Figure 3. In WEO-2008, "the integration of the WEM into a general equilibrium model, started in 2007, was taken a step further, in order to model more precisely the feedback links between energy markets and the macro-economy" (IEA 2008 p. 61). These changes do coincide with a marked increase in the elasticity in Figure 3. Subsequent reports (e.g. IEA 2011, 2013, 2014)

\footnotetext{
${ }^{5}$ The decomposition results are only very slightly different if instead the projected growth rate is used together with the actual elasticity first and then the residual found.
} 
increasingly emphasized that energy price projections were derived iteratively rather than being based completely on exogenous assumptions, but noted that the model was still a partial equilibrium model.

As the actual elasticities in recent years are based on very short time series that do not include a recession, they are likely to overestimate the true elasticity. Csereklyei and Stern (2015) find that, contrary to conventional wisdom, the elasticity of energy use per capita with respect to GDP per capita increases with GDP per capita. Therefore, we should not necessarily expect the elasticity of interest here to decline over time. Instead, Csereklyei and Stern (2015) find that the slow growth of energy use in high income countries relative to upper middle income countries is mostly due to convergence effects - countries that were initially relatively energy intensive have converged in energy intensity with those that initially had relatively low energy intensity. It is likely, therefore, that since 2008 the $W E O$ has overestimated the elasticities that will eventuate over the full projection horizons of 2030 to 2040.

The projected elasticities for recent years in Figure 3 actually understate the elasticities that IEA expects to eventuate. IEA has stated that they expect countries to implement more policies than in the Current Policies scenario in subsequent years and that their central scenario is now the New Policies scenario" (IEA 2015). One possible reason for overestimating future elasticities is that not all stated policies are implemented as effectively as IEA expects and over time there have been more and more explicit policies for IEA to incorporate in the WEM. The WEM now takes into account thousands of individual policies and measures (IEA 2011).

Another possible reason why both IEA and the IPCC consensus projections overestimate the future decline in energy intensity is that they do not take the economy-wide rebound effect sufficiently into account (Saunders 2013). Improvements in pure energy efficiency lower the cost of providing energy services and thus, via the law of demand, result in greater consumption of those energy services, so that the reduction in energy use is less than the improvement in energy efficiency. Economy-wide, this micro-level direct rebound effect may be amplified or attenuated by indirect rebound, general equilibrium, and dynamic effects (Stern 2011). There are many empirical estimates of the micro-level direct rebound effect but there are no good empirical estimates of the economy-wide rebound effect. Simulation models show that the economy-wide rebound could be larger or smaller than the micro-level rebound (Turner, 2013). Depending on assumed model parameters, Turner (2009) finds that 
the economy-wide rebound effect for the UK could range from a negative value - where energy use falls by more than energy efficiency improves - to more than $100 \%$ - where energy use actually increases following an efficiency improvement.

However, the consensus is that the effect is positive and larger than the micro-level direct rebound effect (Saunders 2008; Stern 2011). Stern (2012) finds that reductions in energy intensity are considerably less than improvements in energy efficiency at the economy-wide level. The most important countervailing factor was substitution of energy for labor. Van Benthem (2015) and Csereklyei et al. (2016) find that energy intensity is similar in today's developing countries to what it was in today's developed countries when they were at the same per capita income level, despite the huge improvements in energy efficiency in many technologies, which are used in both developed and developing countries alike. ${ }^{6}$

In conclusion, the future decline in energy intensity is likely to be less than projected in the most recent WEO's despite their using more sophisticated and detailed modeling of the economy and energy policies. A possible reason for this is that they underestimate the size of the economy-wide rebound effect. This may also be the case for other projections of future energy intensity aggregated by the 2014 IPCC report. Empirical estimation of the economywide rebound effect and incorporation of the findings into energy projection models should be a research priority for energy economics and the climate policy community.

\section{Data}

I used the BAU, Reference, or Current Policies projection of world economic growth rates and the level of world energy use from each $W E O$ for each sub-period and specific year that they were given, respectively. WEO-1999 did not report specific quantities of projected future energy use but did state that energy use was expected to rise by $65 \%$ by 2020 and that the same economic growth rate projections were used as in WEO-1998. For WEO-1995 and WEO-1996 I used the "capacity constraints" scenario, which assumes historical trends in energy efficiency. In the case of WEO-1996, where separate market (MER) and purchasing power parity (PPP) exchange rate economic growth rate projections were given I use the PPP growth rate. WEO-1994 and WEO-1995 give only a MER world economic growth rate. This

\footnotetext{
${ }^{6}$ Changes in energy intensity are of course not just the result of energy efficiency improvements and the rebound effect. Independent changes in other factors and the efficiency with which they are used and structural change in the economy can all have an effect (Stern, 20012; Saunders, 2015).
} 
is $0.1 \%$ p.a. lower than the MER growth rate in WEO-1996 in 1995 and $0.3 \%$ p.a. lower in 1994 and so I assume that the respective PPP growth rates are also $0.1 \%$ and $0.3 \%$ p.a. lower. I used actual world GDP in 2011 PPP dollars from the World Bank's World Development Indicators for the base year of the projections in the report and projected GDP at future dates using the given growth rates. I then divided the projected energy use at each future date by projected GDP to give projected energy intensity. I then computed the growth rate of energy intensity in each future sub-period.

\section{References}

Aleklett K, Höök M, Jakobsson K, Lardelli M, Snowden S, Söderbergh B (2010) The peak of the oil age - analysing the world oil production reference scenario in World Energy Outlook 2008. Energy Policy 38(3): 1398-1414.

Clarke, L. et al. (2014) Chapter 6: Assessing transformation pathways. In: Edenhofer, O. et al. Contribution of Working Group III to the IPCC $5^{\text {th }}$ Assessment Report. Cambridge University Press, Cambridge.

Csereklyei Z, Rubio-Varas MdM, Stern DI (2016). Energy and economic growth: The stylized facts. Energy Journal 37(2): 223-255 (2016).

Csereklyei Z, Stern DI (2015) Global energy use: Decoupling or convergence? Energy Economics 51: 633-641.

International Energy Agency (1994) World Energy Outlook: 1994 Edition. OECD, Paris, Paris.

International Energy Agency (1995) World Energy Outlook: 1995 Edition. OECD, Paris. International Energy Agency (1996) World Energy Outlook: 1996 Edition. OECD, Paris. International Energy Agency (1998) World Energy Outlook: 1998 Edition. OECD, Paris. International Energy Agency (1999) World Energy Outlook: Looking at Energy Subsidies: Getting the Prices Right - 1999 Insights. OECD, Paris.

International Energy Agency (2000) World Energy Outlook 2000. OECD, Paris.

International Energy Agency (2001) World Energy Outlook: Assessing Today's Supplies to Fuel Tomorrow's Growth - 2001 Insights. OECD, Paris. 
International Energy Agency (2002) World Energy Outlook 2002. OECD, Paris.

International Energy Agency (2003) World Energy Investment Outlook: 2003 Insights. OECD, Paris.

International Energy Agency (2004) World Energy Outlook 2004. OECD, Paris. International Energy Agency (2005) World Energy Outlook 2005: Middle East and North Africa Insights. OECD, Paris.

International Energy Agency (2006) World Energy Outlook 2006. OECD, Paris. International Energy Agency (2007) World Energy Outlook 2007. OECD, Paris. International Energy Agency (2008) World Energy Outlook 2008. OECD, Paris. International Energy Agency (2009) World Energy Outlook 2009. OECD, Paris. International Energy Agency (2010) World Energy Outlook 2010. OECD, Paris. International Energy Agency (2011). World Energy Outlook 2011. OECD, Paris. International Energy Agency (2012) World Energy Outlook 2012. OECD, Paris. International Energy Agency (2013) World Energy Outlook 2013. OECD, Paris. International Energy Agency (2014) World Energy Outlook 2014. OECD, Paris. International Energy Agency (2015) World Energy Outlook 2015. OECD, Paris. International Energy Agency (2016) World Energy Outlook 2016. OECD, Paris. Jotzo F, Burke PJ, Wood PJ, Macintosh A, Stern DI (2012) Decomposing the 2010 global carbon dioxide emissions rebound. Nature Climate Change 2(4): 213-214.

Marangoni G, Tavoni M, Bosetti V, Borgonovo E, Capros P, Fricko O, Gernaat DEHJ, Guivarch C, Havlik P, Huppmann D, Johnson N, Karkatsoulis P, Keppo I, Krey V, Ó Broin E, Price J, van Vuuren D P (2017) Sensitivity of projected long-term CO2 emissions across the Shared Socioeconomic Pathways. Nature Climate Change 7: 113-117

Metayer M, Breyer C, Fell H-J (2015) The projections for the future and quality in the past of the World Energy Outlook for solar PV and other renewable energy technologies. 
Proceedings of the $31^{\text {st }}$ European Photovoltaic Solar Energy Conference, September 14-18, Hamburg Germany.

Pretis F, Roser M (2016) Carbon dioxide emission-intensity in climate projections: comparing the observational record to socio-economic scenarios. University of Oxford, Department of Economics, Discussion Paper Series 810.

Saunders HD (2008) Fuel conserving (and using) production functions. Energy Economics 30: 2184-2235.

Saunders HD (2013) Historical evidence for energy efficiency rebound in 30 US sectors and a toolkit for rebound analysts. Technological Forecasting and Social Change 80: 1317-1330.

Saunders HD (2015) Recent evidence for large rebound: elucidating the drivers and their implications for climate change models. Energy Journal 36(1): 23-48.

Stern DI (2011) The role of energy in economic growth. Annals of the New York Academy of Sciences 1219, 26-51..

Stern DI (2012) Modeling international trends in energy efficiency. Energy Economics 34, 2200-2208.

Turner K (2009) Negative rebound and disinvestment effects in response to an improvement in energy efficiency in the UK economy. Energy Economics 31: 648-666.

Turner K (2013) "Rebound" effects from increased energy efficiency: a time to pause and reflect. Energy Journal 34(4): 25-43.

Van Benthem AA (2015) Energy leapfrogging. Journal of the Association of Environmental and Resource Economists 2(1): 93-132. 
Figure 1. World Energy Outlook 2016 Energy Intensity Projections vs Recent History

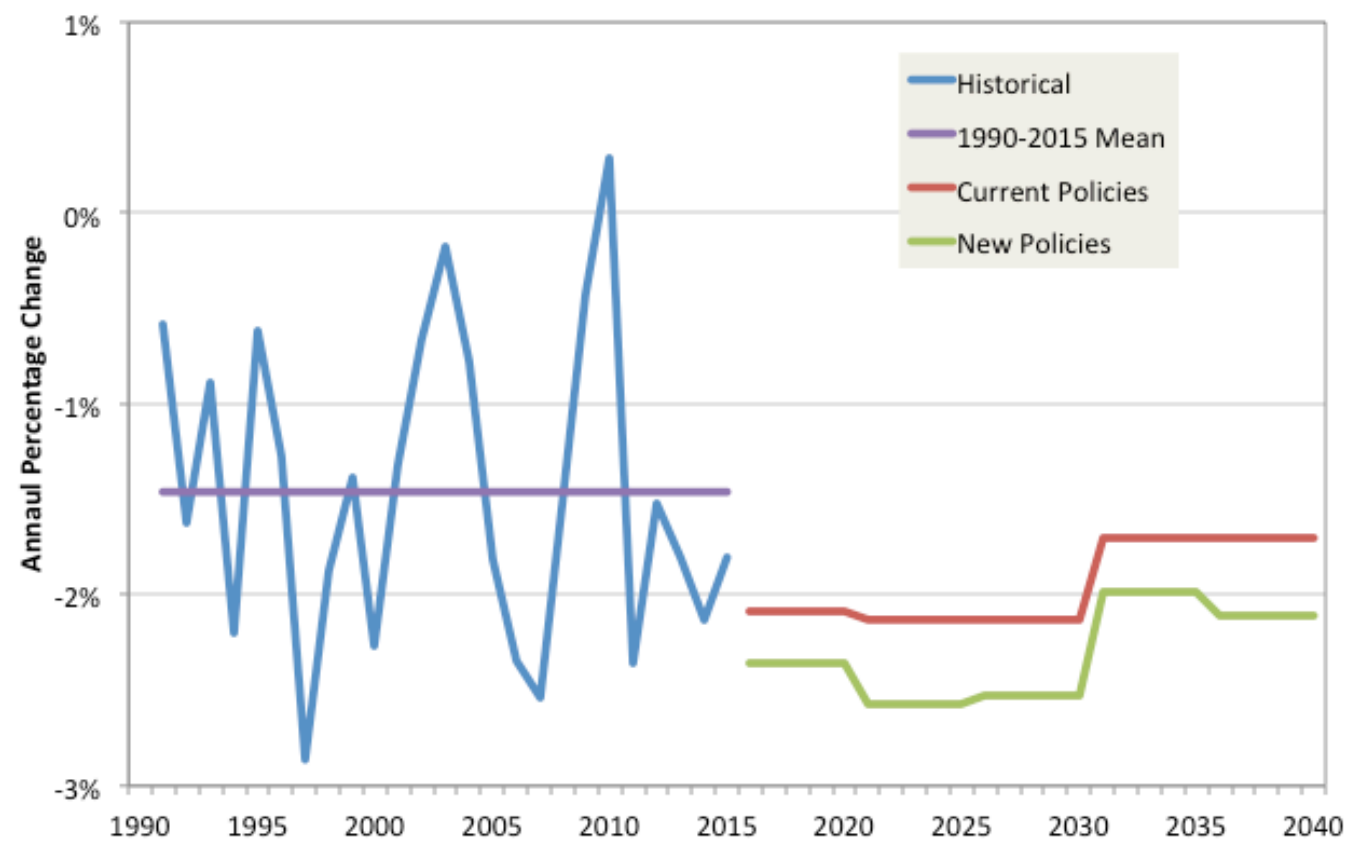


Figure 2. Mean Annual Difference in Actual Rate of Change in Energy Intensity in Excess of Projected Growth Rate

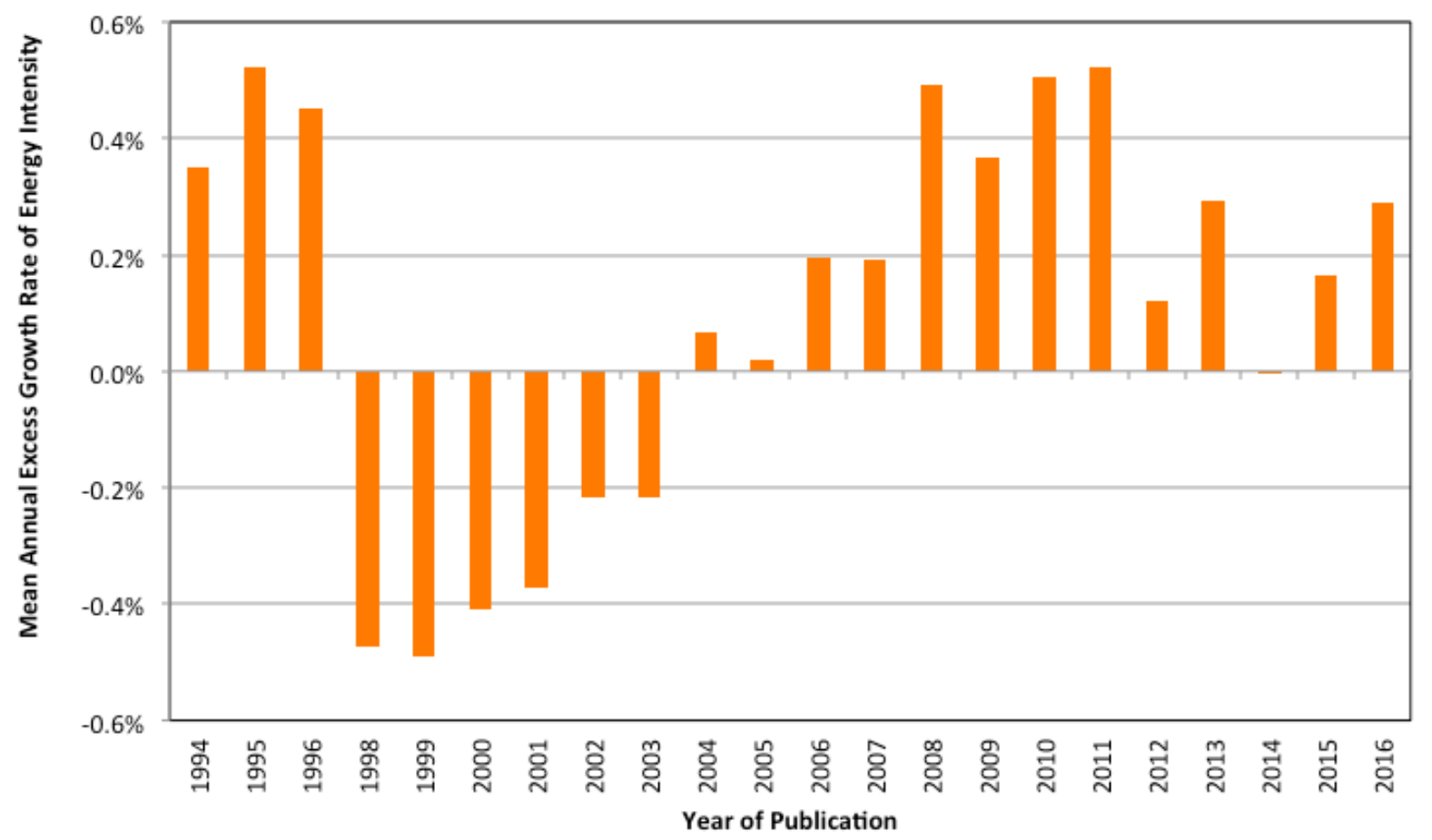

Notes: The dates refer to the publication date of the WEO. The percentage is the mean annual difference between the percentage rate of change in actual energy intensity and projected energy intensity from the base year of the respective WEO through 2015 for WEO-1998 forward. For WEO-1994 to WEO-1996 the projection error is computed through 2010. Because the base year of WEO-2015 is 2013 and of WEO-2016 is 2014 it is possible to compute a projection error for these two latest reports. 
Figure 3. Actual and Projected Elasticities of Energy Intensity with Respect to Economic Growth

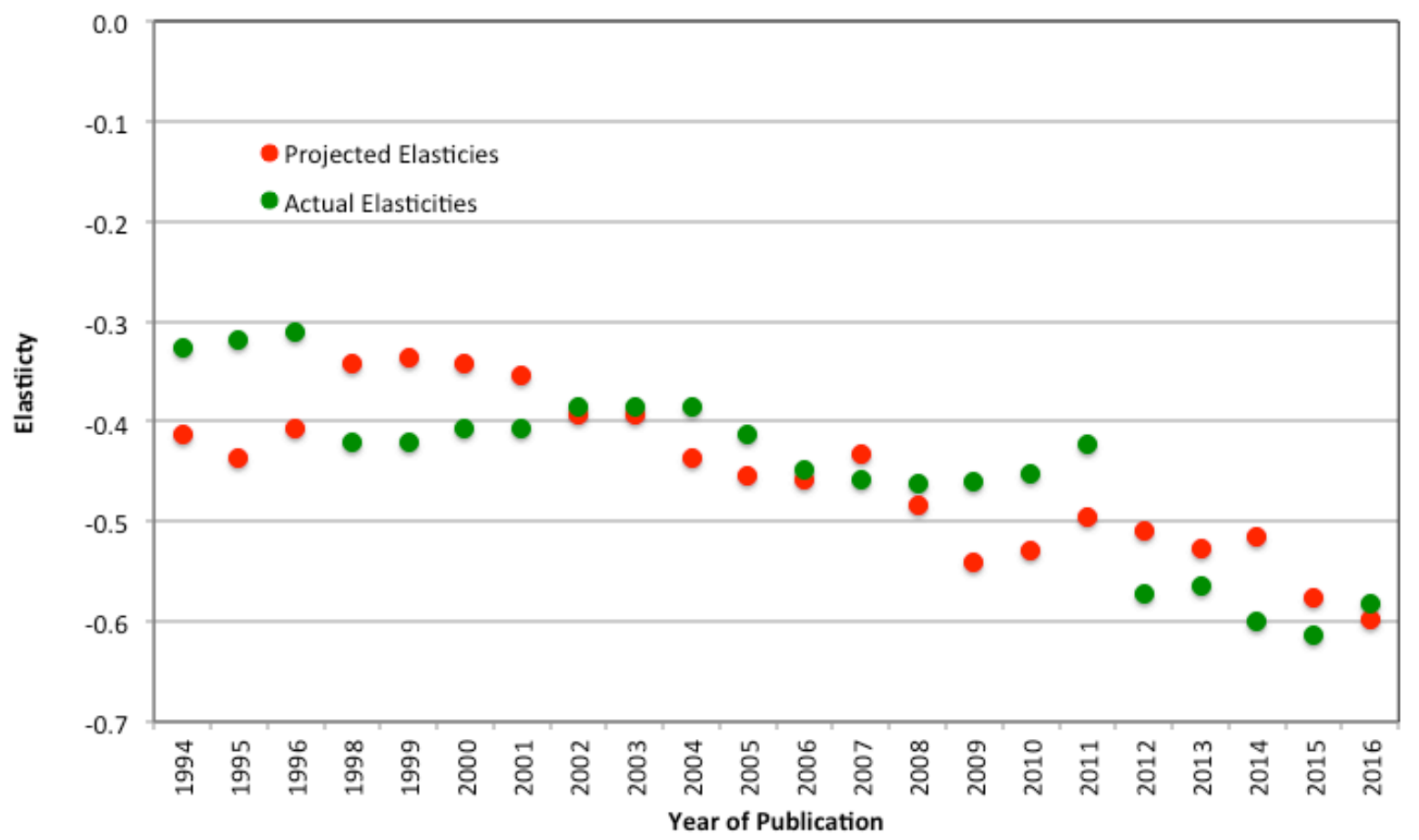

Notes: The dates refer to the publication date of the WEO. Both elasticities are computed from the base year of the WEO through 2015 for WEO-1998 forward. For WEO-1994 to WEO-1996 the projection error is computed through 2010. 
Figure 4. Decomposition of Projection Error

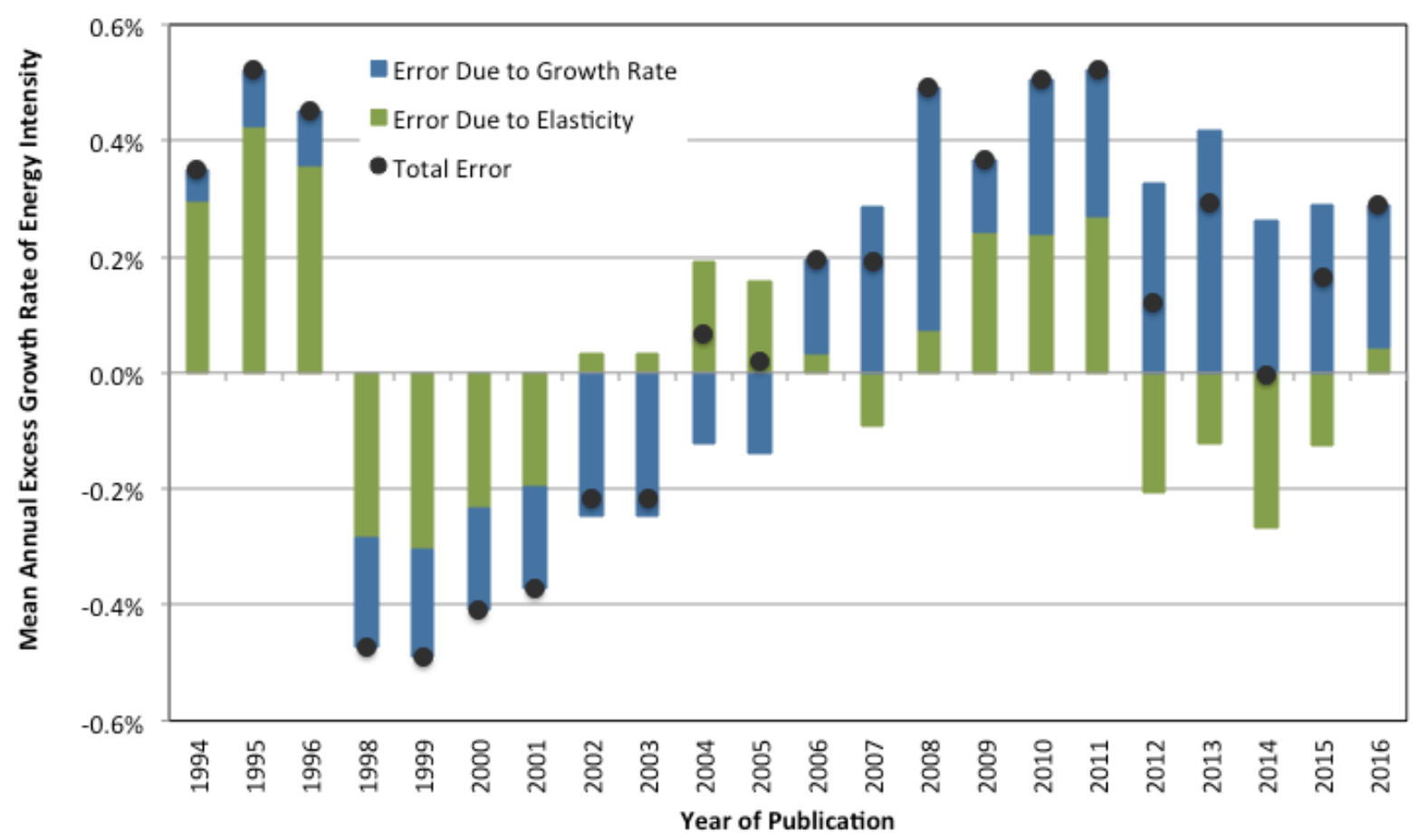

Notes: The dates refer to the publication date of the WEO. Both elasticities are computed from the base year of the WEO through 2015 for WEO-1998 forward. For WEO-1994 to WEO-1996 the projection error is computed through 2010. 